\title{
Research on Crime Prevention Based on the Economics of Crime
}

\author{
Yanli $\mathrm{Li}^{1, *}$ \\ ${ }^{1}$ University of Sydney, Liaoning, China \\ ${ }^{*}$ Corresponding author. Email: 2240341639@qq.com
}

\begin{abstract}
In the research of criminology, crime prevention is a fundamental and strategically important subject. This article attempts to study crime prevention goals, basic theoretical assumptions, best effects and limits from the perspective of criminal economics, using economic analysis methods, with a view to attracting new ideas and arousing academic attention to this issue.
\end{abstract}

Keywords: Criminology, Criminal Economics, Crime Prevention, Economic Analysis

\section{INTRODUCTION}

Criminal behavior is an anti-social behavior that disrupts social order and disturbs social peace. Therefore, no matter in any society, there are criminal laws that stipulate that criminal acts should be punished in order to maintain social order and ethics. Criminal law is a discipline that focuses on the establishment of a crime and its penalty consequences. However, to effectively prevent the occurrence of criminal acts, it is far from enough to study the criminal law of how to convict and send penalties. Although the crimes committed by various offenders may be the same, the reasons for the crimes are very different. The dangers are also different. Therefore, it is necessary to study the characteristics of the inherent personal physical and mental qualities of various criminals and the characteristics of external social environmental factors in order to clarify the various reasons that make the criminals fall into crimes and seek reasonable crime prevention Countermeasures, this is the so-called research field of criminology. In criminology research, crime prevention is an important subject with a fundamental and strategic nature, and it is the fundamental starting point and destination of criminology research. Crimes need to be prevented. There is no dispute on this point [1]. What is controversial is what is the goal of crime prevention, and should there be "zero tolerance" for crime? How to prevent to receiving the best results? These disputes are not purely academic disputes, but are generally concerned by the governments and the public of all countries and regions in ancient and modern countries and regions. Different understandings of crime prevention can even trigger great social disputes. Therefore, clarify the goal of crime prevention, clarify the best effect that crime prevention should achieve, and delineate the limit that crime prevention should achieve [2]. For understanding the meaning of crime prevention, correctly summarizing the experience of crime prevention and upgrading it to crime prevention It is of great significance to effectively guide crime prevention work based on its general theory. There are many research paths for crime prevention, and the answers to the above questions are different. So which path should we choose? It is worth noting that in the recent period, economic analysis methods have gradually penetrated into various fields of law. Among them, economic analysis of criminal acts has developed particularly rapidly. More and more economists and jurists have begun to conduct cross-study on criminology and economics, and the methods and theoretical results of criminal economic analysis have gradually matured, which has given birth to a new discipline, criminal economics. The theory of criminal economics focuses on explaining specific crime prevention goals from an economic sense, predicting the consequences of specific criminal policies, and using economic analysis tools to put forward corresponding policy opinions. Criminal economics has contributed some analysis methods that are different from other disciplines on how to prevent crimes, and put forward policy opinions on crime prevention based on efficiency, which are deeply valued. Therefore, this article is not presumptuous, and attempts to use the theory of criminal economics on the basis of summarizing the previous research work to 
explain the goals, theoretical presumptions, best effects and limits of crime prevention, in order to start a discussion. Arouse the attention of academic circles to this issue.

\section{BASIC GOALS OF CRIME PREVENTION}

From the perspective of criminal economics, the primary goal of crime prevention is efficiency. The socalled efficiency refers to the most effective use of social resources to satisfy human desires and needs. From the perspective of criminal economics, compliance with the law is not unconditional, but requires the use of a certain scale of social resources and the scale of punishment. The resources invested by society for crime prevention are not limitless but extremely limited [3]. Therefore, it is necessary to determine a reasonable scale of resource expenditure and punishment to ensure maximum social welfare. The efficiency of crime prevention in the perspective of criminal economics is to provide as many members of society as possible with the most complete protection of legal interests given the operating technical level and scarce resources of the criminal justice system. Without making any other members of society worse, if it is impossible to make further resource allocation to enhance the protection of the legal interests of any other members of society, it can be considered that this resource allocation is efficient, the so-called so-called Pareto is optimal. This configuration is always Pareto optimal, and vice versa. In addition to efficiency, does the goal of crime prevention need to pay attention to justice? Some scholars believe that, at least in the field of economics, the concept of justice is not an independent evaluation principle, so it cannot be compared with efficiency. In fact, economics is not only concerned with efficiency, but also with justice [4]. That being the case, can we ignore the issue of justice when doing economic analysis of crime to determine the limits and effects of crime prevention? Obviously not. However, from an economic point of view, there may sometimes be a certain degree of trade-off between efficiency and justice. But this does not prevent both from becoming the basic theme and value goal pursuit of crime prevention from the perspective of criminal economics. In fact, the question of how to make tradeoffs between efficiency and justice depends to a large extent on economic analysis.

\section{THE MOST BASIC THEORETICAL MODEL OF CRIME PREVENTION}

To use the analytical methods of economics to study crime, the first recommendation is Professor Gary Becker. In "Economic Analysis of Human Behavior", he used economic methods for the first time to study crime, a social problem that traditionally seemed unrelated to economics. Professor Gary Becker's research shows that an effective theory of criminal behavior is only an extension of the commonly used choice theory in economics. It does not require moral decadence, lack of psychological function, and genetic characteristics to explain criminal behavior. Specifically, crime is also a kind of rational behavior. People will commit crimes only when the benefits of crime exceed the costs. People will consider the probability of being punished and the severity of the punishment in advance, compare the cost of crime and the size of the crime proceeds, and then decide whether to commit a crime. Therefore, the certainty of punishment and the severity of punishment can deter crime. Since then, the theoretical research of criminal economics has been based on the theory of Professor Gary Becker. Professor Gary Becker believes that in order to determine how to deal with crime in the best way, a mathematical model that can reflect the benefits and costs of crime must be established.[5]

Professor Gary Becker pointed out that from the perspective of criminal economics, the motivation for banning and restricting certain activities with criminal sanctions is to worry that the social life interests of other members of society will be harmed (that is, legal interests infringement). The amount of damage will rise as the level of criminal activity rises.

\section{LIMITS OF CRIME PREVENTION}

It is clear what kind of behavior should be prohibited by punishment, but how much resources should the state and society invest in preventing crime? This involves the boundary of crime prevention. Criminal economics provides quite shocking answers in this regard. When the crime rate rises, the instinctive response of the state and society is to invest more resources to prevent crime. But this investment is not infinite. As Professor Mankiw said, its marginal quantity should be considered. In the analysis based on criminal economics, we must consider the social welfare brought by crime prevention that can increase with the social cost required for every additional unit of resource input. If you consider that the marginal revenue is diminishing and the marginal cost is increasing, then one of the most famous formulas in economics: comes in handy. This means that the country and society should continue to invest resources to prevent crime until the marginal cost of crime prevention equals the marginal benefit, and resource investment beyond this equilibrium point is not effective.

Such a conclusion may lead to surprising results: from the perspective of criminal economics, it is not necessary to completely prevent any crime. There will always be a certain equilibrium point, which determines what level of crime prevention activities should reach, beyond this level, the total social welfare will decline instead. In this regard, it is impossible, and there is no need to completely eliminate any crime to achieve "zero 
crime." Because with the continuous increase of the marginal cost of crime prevention and the continuous decline of the social marginal benefits obtained, it will always lead to the optimal level of crime prevention at a certain equilibrium point. Beyond this level, the total social welfare will decline, and society will suffer more unnecessary losses than crimes. The above conclusion, in a nutshell, is to study how many crimes can be tolerated and how many crimes can be unpunished from the perspective of criminal economics to ensure that the welfare of society is maximized. This sounds really unpleasant, and it is very likely to be unacceptable, because in the eyes of the general public, the less crime the better, the best effect of crime prevention is to eliminate all crimes in society, and the above conclusions are consistent with This view seems to run counter to. But the charm of economic analysis of criminology is precisely here: it does appreciate the "eager mood" of "to achieve zero crime", but it also needs a "calm mind" that is good at using economic analysis methods.

\section{THE BEST EFFECT OF CRIME PREVENTION AND ITS REALIZATION}

Professor Liszt once said: "Criminal law is an insurmountable barrier to criminal policy." It is worth mentioning that, to some extent, the analysis of criminal economics has also delineated an "insurmountable barrier" for criminal policies to prevent crime. Generally speaking, criminal policy, as a countermeasure for the country to use the criminal law system to effectively and reasonably confront and prevent crime, needs to follow the principle of last resort, humanity, rule of law, and guilt. However, the study of criminal economics shows that it is impossible to formulate criminal policies to prevent crime without considering the constraints of criminal justice resources. As shown in Figure 1, if the limits of criminal justice resources are represented by the budget constraint line, and the social utility that follows the principle of item by item is represented by the indifference curve, then the point that can maximize social utility is the budget constraint line and no The tangent point $\mathrm{A}$ of the difference curve, at this point, crime prevention achieves the best results. Point B represents the impossible social utility, while point $\mathrm{C}$ represents the situation where the criminal justice resources are not fully utilized and the optimal state is not reached, so neither is acceptable. From this point of view, the analysis of criminal economics has indeed delineated an "insurmountable barrier" for criminal policies to prevent crime, that is, efficiency. The efficiency principle has therefore become the most important principle in criminal policy, because it determines the boundaries and scope of other principles.

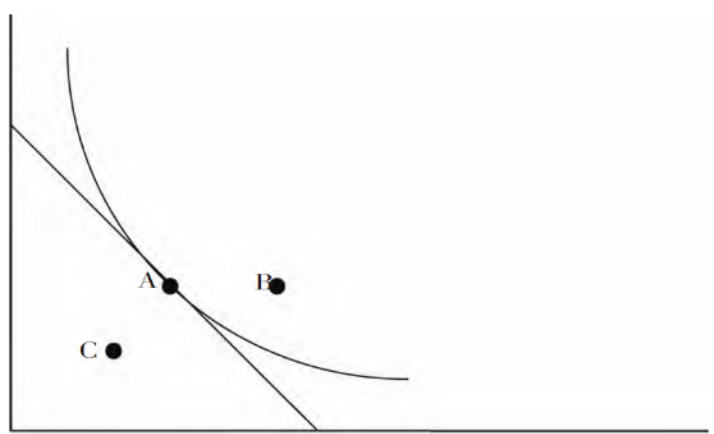

Figure 1 A balanced analysis of criminal justice resources and social utility

What is confusing is that there are more than one type of criminal justice resources. For decision makers of criminal policy to prevent crime, how should various resources be allocated to maximize efficiency? Professor Samuelson's "law of equal margin" provides us with the answer: assuming that all criminal justice resources are expressed in $\mathrm{RMB}$, then the social benefits generated by the last unit of RMB spent on any aspect of crime prevention must be equal to The social benefit generated by the last unit of RMB spent on any other aspect is the same. The reason is simple: if the social benefit generated by the last unit of RMB spent on one aspect of crime prevention is higher than the social benefit generated by the last unit of RMB spent on any other aspect, then the decision-maker will continue to invest This resource, until the law of diminishing marginal returns makes the social benefits generated by the last unit of RMB spent in this area the same as the social benefits generated by the last unit of RMB spent on any other aspect.

\section{CONCLUSION}

In today's criminology research, it is common to use economic analysis methods. The reason is simple. Fundamentally speaking, law is a way of organizing human society and the main structure of social order, which permeates every corner of social life. Unfortunately, the problem-oriented legal science itself does not have any special research methods, and most of its tools are borrowed from other disciplines. Economics uses mathematics and logic as the basic theoretical tools, so it has inherent consistency that other social sciences do not have. It is easiest to objectively verify the accuracy and validity of knowledge. Therefore, in criminal law and even It is not surprising that the theoretical construction and analysis methods of economics are used in criminological research to obtain answers with the greatest possible accuracy. From this point of view, it is not only reasonable and feasible to use the analytical methods of criminal economics in criminology, it is even necessary to some extent. However, it should also be pointed out that economic 
analysis is only one of the ways for human beings to understand and grasp the world. It has its own scope and limitations. It does not represent the entire content of human behavior and society. This method is impossible to truly fully grasp the complicated life world. As Professor Amartya Sen said, in a sense, the scope of economics is very narrow. Even if economic analysis is used internally in economics, it is "not very satisfactory." Many theoretical constructions "not only affect the system The description is extremely simple, and the view of human behavior is also very narrow." Applying it hastily to other fields of social science is tantamount to "Alexander went to Persia without first establishing control over Macedonia." Therefore, the socalled "economic imperialism" that puts economic analysis above any discipline and reduces all the complicated social life phenomena into the theoretical paradigm of economics is not enough. In this regard, the above-mentioned theoretical expressions of crime prevention constructed using criminal economics cannot explain the entire content of crime prevention, nor can it replace the different answers to this question made by other disciplines based on different perspectives. It only expresses the answer to this question based on economics, for decision-makers to use as a necessary reference when formulating criminal policies for crime prevention. Criminal economics has its own theoretical limitations and applicable limits. Correctly understanding these limitations and limits to ensure that they are not exceeded can ensure the reliability of the answer.

\section{REFERENCES}

[1] Zhang Ganmei. The Original Theory of Criminology [M]. Hanlin Publishing House, 1985.

[2] Kang Shuhua, Zhang Xiaohu, editor-in-chief. Criminology [M], Peking University Press, 2004.

[3] [US] Paul Samuelson, William Nordhaus. Microeconomics (19th edition) [M]. Xiao Chenzhu, translated. People's Posts and Telecommunications Publishing House, 2012.

[4] [America] Hal Fanlian. Microeconomics: Modern Views [M]. Fei Fangyu et al., translated. Gezhi Publishing House-Shanghai Sanlian Bookstore-Shanghai People's Publishing House, 2011.

[5] Li Y, Chen A, Zhou Y, et al. Research on the assessment indicators for crime prevention lighting in residential areas based on AHP and Entropy Weight[J]. MATEC Web of Conferences, 2016, 61:04009. 